\title{
Productivity of soya bean depending on inoculation and fertilizers in conditions of Polisya of Ukraine
}

\author{
V. Didora, \\ Doctor of Agricultural Sciences \\ O. Stupnitska \\ Zhitomir National Agroecological University
}

The purpose. Detection and justification of influence of norms of artificial fertilizers, inoculations of seeds and foliar application on formation of productivity and quality of soya bean in Polisya. Methods. Agrochemical (for determination of chemical composition of soil, plants), mathematical (dispersing), biometrical (for determination of formation and activity of symbiotic apparatus). Results. Formation is shown of tubercles depending on inoculation of seeds and foliar application on the background of artificial fertilizers. The amount of biological nitrogen and equivalent of ammonium nitrate is calculated. It is fixed that inoculation and foliar application on the background of artificial fertilizers in dose of N60P60K60 promotes formation of tubercles on a rootage (73 pieces in comparison with alternative without fertilizing). Conclusions. Increase of crop of early ripening variety KiVin at application of artificial fertilizers in dose of N60P60K60, inoculations and foliar application has made 1,3 t/hectare.

Key words: soya bean, inoculation, foliar application, formation of tubercles, biological fixation of nitrogen, productivity.

Vegetable albumen is the most important constituent of food and fodder resources, the use of which has a considerable impact on people's health, their wellbeing, lifespan and level of life. At the end of the $20^{\text {th }}$ century a part of vegetable albumen amounted to $70 \%$, whereas that of an animal albumen amounted to $30 \%$ in a common balance of this product.

Soybean is a high-tech crop, so a scientific approach to the improvement of soybean growing technology with due regards to region conditions as well as to crop biological peculiarities is very important. It is necessary to study the impact of seeds pre-seeding treatment with a complex of microelements, the seeds inoculation as well as foliar fertilization on soybeans yield. The introduction of effective, competitive technologies with a high pay-back energy level, as well as of technologies adapted to the environmental conditions of soybean growing and based on the scientifically substantiated soybean distribution in rotation, on a differentiated soil tillage as well as on a rational and improved system of mineral and bacterial fertilization will provide a high and steady soybean yields.

The analysis of the latest research and papers.

Under the condition of soybean growing in different soil and climatic conditions the demand for nutritional elements is different. There is no common opinion as for soybean mineral fertilization on light-grey soils of Polissia.

The highest soybean yield is received under the condition of its growing on rich in organic and mineral substances soils with the reaction of soil solution close to neutral $(\mathrm{pH}=6.5)$.

It has been determined that the introduction of phosphorus and potassium fertilizers in a norm of P60K60 before the main soil cultivation and the introduction of $\mathrm{N}_{60}$ before the pre-seeding soil cultivation as well as seeds treatment with inoculants before sowing, provide the highest soybean yields $-2.19-2.53 \mathrm{t} / \mathrm{ha}$. The increase in yield as compared to the yield on the plot with a control variant was $0.62 \mathrm{t} / \mathrm{ha}$.

The nitrogen fertilizers irrespective of their form and under the condition of both introducing $30 \mathrm{~kg}$ of nitrogen and seeds inoculation, increase the seeds yield by $100-220 \mathrm{~kg} / \mathrm{ha}$, and under the condition of N60 introduction the yields increase by $250-410 \mathrm{~kg}$.

In the open air there is $76 \%$ of nitrogen in the form of $\mathrm{N}_{2}$ gas which is inaccessible for plants fertilizing. But due to the legumes unique capability to form symbiotic relations with bacteria Bradyrhizobium and 
Rhizobium $\mathrm{N}_{2}$ gas converts into the nitrogen ammonia form which can be used by the plants. This interrelation occurs in nodules where are the appropriate bacteria.

According to the data, soybeans get up to $70 \%$ of nitrogen on account of its biological fixation from the air due to the symbiosis with nodules bacteria.

The goal of the research - to determine and scientifically substantiate the impact of mineral fertilizers norms, seed inoculation and foliar fertilization on soybean yield and quality in Polissia area.

The object of the research is the process of soybean growth and development, the formation of yield and seeds quality as well as nitrogen accumulation in the soil.

The subject of the research: the norms of mineral fertilizers, seeds inoculation with Rhizoguminum and foliar fertilization with a complex fertilizer on a chelated background" Christalon Universal", as well as soy productivity.

The methods of the research. The research was conducted during 2012-2014 in the research field of Zhytomyr National Agroecological university in Cherniahiv district Zhytomyr oblast. The analytical research was conducted at the university department of crop produce storing and processing.

The research was conducted in a four- time frequency, the variants location was systematic. The cultivation area was $31.2 \mathrm{~m}^{2}$, the registration plot was $25.3 \mathrm{~m}^{2}$.

The soil on the research plot is light grey, the soil density is $1.17-1.3 \mathrm{~g} / \mathrm{cm} 2$, the common texture is $48-$ $51.6 \%$, the nitrogen content is $61.6 \mathrm{mg} / \mathrm{kg}$, the movable forms of $\mathrm{P}_{2} \mathrm{O}_{5}$ is $160 \mathrm{mg} / \mathrm{kg}$, exchange $\mathrm{K}_{2} \mathrm{O}$ is $65 \mathrm{mg} / \mathrm{kg}, \mathrm{pH}=5.9$.

To increase the yield and soybean quality, the seeds were treated with Rhizoguminum inoculant in a norm of $200 \mathrm{~g} / 100 \mathrm{~kg}$ of soybean seeds, which contains specific virulent active strains of nodules bacteria Bradirisobium japonicum aimed at improving the symbiosis of the plants with nodules bacteria. In the period of flower-bud formation a foliar plants fertilization was held with a complex fertilizer on a chelated background" Christalon Universal" at a norm of $2 \mathrm{~kg} / \mathrm{ha}$ which contains $\mathrm{N}_{18} \mathrm{P}_{18} \mathrm{~K}_{18}$ and a complex of microelements.

The nodules location, amount and mass on the plants roots as well as the amount of biological nitrogen were determined according to the method of G.S. Posipanov. As the results of the research testify, soybean belongs to the crops in which the nodules ate located close to and around the root at a depth of $10-12 \mathrm{~cm}$ with a radius up to $12 \mathrm{~cm}$.

To determine the presence of nodules on the plants roots in different growth and development phases, the soil monoliths $50 \mathrm{~cm}$ in diameter and $0-20 \mathrm{~cm}$ in depth were chosen. The soil roots were washed under water in the sieves with the openings $1 \mathrm{~mm}$ in diameter. The clayey soil particles were refined with a soft brush under running water above the sieve. After a full purification of roots from soil the nodules were dried by means of the filtration paper, separated from the roots, weighed and their amount was determined with lelemoglobin and without it.

The granulated superphosphate was introduced before the main soil cultivation in amount of $19.5 \%$ of active material (Standard 5956-78) and potassium chloride-60\% of active material (Standard 4568-96). In spring nitrate fertilizer-34\% of active material was introduced into the soil (Standard2-85E).

The statistical analysis of soybean yield data was conducted according to the standard practice.

The results of the research. The weather conditions in the period of research differed greatly. 2012 was the most favorable year for soybean growth and development. That year the plants got enough productive moisture and provided a high yield level. 2013 was a temperately humid year and in 2014 the soy plants were subjected to a long-standing drought.

The amount of joints on the stem, that of branches as well as lower branches and the beans on them are the morphological peculiarities which affect the soy bean yield and depend on the strain's genetic peculiarities. The research proved that mineral fertilizers had great impact on linear growth indexes of the main plant's stem. On the plots with inoculated seeds the plants were up to $91.9 \mathrm{~cm}$ high. There was a tendency to height increase under the condition of applying the fertilizers. The seeds inoculation on the background of applying the fertilizers at a dose of $\mathrm{N}_{60} \mathrm{P}_{60} \mathrm{~K}_{60}$ contributed to a height increase which was $5 \mathrm{~cm}$ more than in the variants without fertilizers. 
Under the condition of foliar fertilization without fertilizers the plants reached the height of $90.5 \mathrm{~cm}$ that was $4 \mathrm{~cm}$ higher than the control. Foliar fertilization when introducing fertilizers $\mathrm{N}_{60} \mathrm{P}_{60} \mathrm{~K}_{60}$ contributed to height increase by $6 \mathrm{~cm}$ as compared to the variants without fertilizers.

In the research variants when inoculation and foliar fertilization were combined the soy plant height was the highest. It is explained by the process of nodules formation and the use of biological nitrogen. The inoculation and foliar fertilization contributed to the intensive linear stem growth. Its additional growth was 6 $\mathrm{cm}$ higher than in a control variant. A complex effect of inoculation, foliar fertilization and the introduction of mineral fertilizers contributed to the increase in height by $17 \%$ as compared to control. The height of a lower bean affixation is an important index for cutting down the expenses in the period of soy bean harvesting. The height was in direct proportion to the plants height and changed together with it. This index was the highest in the variant of inoculation with the introduction of mineral fertilizers in a norm of $\mathrm{N}_{60} \mathrm{P}_{60} \mathrm{~K}_{60}$ and foliar fertilization and amounted to $12.2-16 \mathrm{~cm}$. The average number of soy beans on a plant and that of seeds in beans was 2.0-2.5 pieces, a 1000 seeds mass was $109-117 \mathrm{~g}$.

Soy plant is one of the legume plants whose root system can store nitrogen in soil on account of its biological fixation from the atmosphere. 2012-2013 were the most favorable research years for the development of nodules and 2014 was dry, so the bacteria symbiosis with the soy plant's root was somewhat suppressed. Thus, in a control variant (without fertilizers) the amount of nodules was 30 pieces, their mass was $182 \mathrm{~kg} / \mathrm{ha}$. When introducing the mineral fertilizers in a norm of $\mathrm{N}_{60} \mathrm{P}_{60} \mathrm{~K}_{60}$ the nodules amount and mass increased by 16 pieces and $70 \mathrm{~kg}$ respectively. In a variant with a foliar fertilization with a complex fertilizer on a chelate basis the nodules amount was 58 pieces per plant, their mass was $217 \mathrm{~kg} / \mathrm{ha}$. Under the condition of mineral fertilizers introduction at a dose of $\mathrm{N}_{60} \mathrm{P}_{60} \mathrm{~K}_{60}$ combined with foliar fertilizing the amount of nodules increased by 41 piece and their mass increased by $62 \%$ as compared to the variant with introducing only foliar fertilization.

The seeds inoculation resulted in a higher nodules amount and correspondingly their mass increased. As compared to the variant without fertilizers, the foliar fertilizing contributed to the increase in the amount of nodules by 40 pieces and by 12 pieces per plant, and their mass by 83 and by $48 \mathrm{~kg} / \mathrm{ha}$. The introduction of mineral fertilizers along with inoculation improved these indexes. In that way, in a variant with the introduction of N60P60K60 plus inoculation, the amount of nodules increased as compared to inoculation by 21 piece, the mass by $82 \mathrm{~kg} / \mathrm{ha}$ or by $30 \%$.

The highest growth in the number of nodules and in their mass was in a variant with a combination of inoculation, foliar fertilizing and mineral fertilizers. The seeds inoculation and foliar fertilizing when applying mineral fertilizers, as compared to the control, contributed to the nodules formation. Their amount increased by 73 pieces per plant, the mass increased by $198 \mathrm{~kg} / \mathrm{ha}$. A combined application of mineral fertilizers at a dose of $\mathrm{N}_{60} \mathrm{P}_{60} \mathrm{~K}_{60}$ plus inoculation and foliar fertilizing had the highest indexes. In this variant the amount of nodules as compared to the variant with the introduction of fertilizers at a dose of $\mathrm{N}_{60} \mathrm{P}_{60} \mathrm{~K}_{60}$ plus foliar fertilizing and $\mathrm{N}_{60} \mathrm{P}_{60} \mathrm{~K}_{60}$ plus inoculation increased by $55 \%, 31 \%, 12 \%$ correspondingly, and the nodules mass increased by $34 \%, 22 \%, 9 \%$ correspondingly.

Our calculations as for nitrogen fixation showed that its smallest amount was in a control variant. The introduction of mineral fertilizers at a dose of $\mathrm{N}_{60} \mathrm{P}_{60} \mathrm{~K}_{60}$ contributed to nitrogen fixation by $45 \%$ more than in a control variant. The introduction of fertilizers on a chelate background" Christalon Universal" and seed inoculation increased nitrogen fixation as compared to the control by $7 \mathrm{~kg} / \mathrm{ha}$ and $25 \mathrm{~kg} / \mathrm{ha}$ correspondingly. The inoculation when applying $\mathrm{N}_{60} \mathrm{P}_{60} \mathrm{~K}_{60}$ contributed to the nitrogen fixation as to the control at a double rate.

Among all the variants, the best indexes of nitrogen fixation and of ammonia fertilizer respectively, were in a variant with a combination of inoculation and foliar fertilizing when applying mineral fertilizers. The amount of nitrogen increased by $169 \mathrm{~kg} / \mathrm{ha}$.

The seed treatment by means of the inoculator Rhyzogumin when applying mineral fertilizers at a dose of $\mathrm{N}_{60} \mathrm{P}_{60} \mathrm{~K}_{60}$ provides an increase in soy seeds yield within $0.8 \mathrm{t} / \mathrm{ha}$. Under the condition of a complex introducing of mineral fertilizers at a dose of $\mathrm{N}_{60} \mathrm{P}_{60} \mathrm{~K}_{60}$ followed by foliar fertilizingwhen applying soy seeds treatment by means of an inoculator, a maximum yield was on the average $3.1 \mathrm{t} / \mathrm{ha}$ in 2012-2014.As compared to other variants a real increase in yield was $1.3 \mathrm{t} / \mathrm{ha}, 1.1 \mathrm{t} / \mathrm{ha}, 0.9 \mathrm{t} / \mathrm{ha}$. 


\section{Conclusions.}

The introduction of mineral fertilizers in a norm of $\mathrm{N}_{60} \mathrm{P}_{60} \mathrm{~K}_{60}$, the inoculation and foliar fertilization do not depress the nitrogen-fixation activity of the microorganisms, but on the contrary, they promote to nodules formation on the root system in amount of 73 pieces as compared to a non- fertilized background.

The yield increase of soybean strain KyWin was $1.3 \mathrm{t} /$ ha when applying mineral fertilizers at a dose of $\mathrm{N}_{60} \mathrm{P}_{60} \mathrm{~K}_{60}$, as well as inoculation and foliar fertilization. In the conditions of Ukraine's Polissia on the light grey soil which is moderately provided with nutritive elements, the increase in soy bean cultivated areas and the application of the intensive technology elements enable to provide soil with biological nitrogen that responds to the equivalent of nitrate fertilizer-318 kg/ha and contributes to 3021 hryvna saving.

\section{Bibliography}

1. A.O. Babych. Modern Production and Soybean Utilization/A.O. Babych. - K.:"Urozhay",1993, - 432 p.

2. Y.A. Gurtovy. The grounds for Ecologically Balanced Intensification of Soybean Growing in Right-bank Forest-steppe Area of Ukraine/Y.A.Gurtovy. - Fodder and Fodder Production. 2011. -Issue. 69. P. 189-194.

3. The Theoretical Substantiation and Methods of Strain Technology Optimization of in Soybean Growing in Forest Steppe Area of Ukraine/[O.A. Babych, S.I. Kolesnyk, S.Y. Kobak, O.Y. Panasiuk and Others]. Fodder and Fodder Production: Interdep. of Themat. Sciences. Collection, 2011. - Issue. 69. - P. 113-121.

4. V.P. Dereviansky. The Methodic Recommendations on Soybean Growing, Recycling and Utilization in Forest-Steppe area of Ukraine/V.P. Dereviansky, V.Y. Kiziakov. - Kyiv, 1998. - 36 p.

5. S.I. Kolisnyk. Soybean Productivity Depending on the Enhanced Nitrogen and Herbicides Doses in Drills Sowings in Forest-Steppe Area of Ukraine/S.I. Kolisnyk, O.M. Venediktov, G.V. Opanasenko,- Fodder and Fodder Production, 2004.- Issue 53.- P. 88-92.

6. M.Z. Tolkanov The Effects of Different Mineral Nitrogen Fertilizers Doses and Forms on Soybean Symbiotic Nitrogen Fixation and Productivity/M.Z. Tolchanov. - Fodder and Fodder Production: Inerdep. Themat. Scient. Collection., 2004.- Issue. 53.- P. 55-62.

7. Bred Erker. Inoculation for Soybean./Bred Erker, Mark Brick. - grain, 2013. - № 1 (82). - P. 87-89.

8.A.v. Kalinichenko. The Mathematic Analysis of the Biological Process of the Symbiotic Nitrogen Fixation and its Impact on Final Product/A.V. Kalinichenko. - Bulletin of Poltava State Agrarian Institute, 2000. - №6. - P. 25-29.

9. G.S. Posypanov. The methods of Studying of the Nitrogen Biological Fixation./G.S. Posypanov. - M.: Agroprom Publishers, 1991. - 299 p.

10. Superphosphate Granulated Made of Phosphate Concentrate without Additives but with Microelements Supplement. Technical Conditions State Standard 5956 - 78.

11. Potassium Chloride. Technical Conditions State Standard 4568 - 95.

12. Nitrate Fertilizer. Technical Conditions State Standards $2-85 \mathrm{E}$. 